\title{
Criatividade e silêncio: encontros e desencontros entre os saberes tradicionais e o conhecimento científico em um curso de licenciatura indígena na Universidade Federal de Minas Gerais
}

\author{
Reciprocity and silence: tensions between the scientific \\ knowledge and traditional knowledge on a course for educators \\ of indigenous people in Universidade Federal de Minas Gerais
}

Juarez MelgaçoValadares ${ }^{1}$ • https://orcid.org/0000-0001-8950-1490

Marta Maria Castanho Almeida Pernambuco ${ }^{2}$

\begin{abstract}
Resumo: Neste trabalho analisamos os impasses decorrentes do encontro entre a cultura acadêmica e os saberes tradicionais em um Curso de Formação Intercultural para Educadores Indígenas da Faculdade de Educação da Universidade Federal de Minas Gerais. Em 2015 ocorreu a disciplina Relação com 0 Conhecimento, iniciada com a pergunta: "Como conhecemos as coisas?". Os discursos dos alunos sobre a natureza do conhecimento científico e do conhecimento tradicional, e os debates acerca do tema foram registrados em um diário de campo. Observamos tanto as formas com as quais os alunos explicaram a aproximação entre as duas maneiras de produzir e validar os conhecimentos em jogo, quanto percebemos momentos nos quais as vozes dos alunos foram silenciadas. Indagamos: o que provocou esse silêncio, uma vez que as aulas foram planejadas para serem dialógicas? Acreditamos que este trabalho traz contribuições para compreender as manifestações da interculturalidade em sala de aula nos cursos de formação para educadores indígenas.
\end{abstract}

Palavras-chave: Interculturalidade. Educação indígena. Formação de professores.

\begin{abstract}
We analyze the tensions that arose from the meeting between academic culture and traditional knowledge in an Intercultural Course for Indigenous Educators (FIEI) of the Faculty of Education of Universidade Federal de Minas Gerais. In 2015 the discipline "The Relation with Knowledge" took place, with the purpose of starting the Course with the following question: "How do we know things?" We seek the discourses of indigenous students about the nature of scientific and traditional knowledge. The data of the discussions were recorded in a field diary. We observed both the ways in which students explained the approximation between the two ways of producing and validating the knowledge in play as we perceived two moments in which the students' voices were silenced. What caused this silence, since the classes were designed to be interactive and dialogical? We believe that explaining these situations provides important contributions to understanding interculturality in courses for indigenous teachers.
\end{abstract}

Keywords: Border culture. Indigenous education. Teacher education.

\footnotetext{
1 Universidade Federal de Minas Gerais (UFMG), Faculdade de Educação, Belo Horizonte, MG, Brasil.

E-mail: <juarezm@ufmg.br>.

${ }^{2}+$ In Memoriam.
} 


\section{Introdução}

\section{Justificativa}

O processo de democratização do país, na década de 1980, trouxe a luta pelo acesso e permanência a uma escola pública de qualidade, criando algumas tensões: de um lado, um universo escolar marcado por lógicas como homogeneidade, igualdade, objetividade, ciência e cultura única; de outro, um mundo social caracterizado pela heterogeneidade, relativismo, subjetividade e cultura local. O respeito com os saberes e com a experiência do novo público que chegava na escola promoveu uma ruptura com o pensamento único que envolvia a cultura escolar, abrindo a perspectiva de uma educação intercultural.

No que se refere à educação em ciências, os estudos sobre concepções prévias e mudança conceitual, ocorridos a partir do final da década de 1970, trouxeram um enriquecimento das experiências didáticas. Desde então vem se pesquisando a interferência dos conhecimentos prévios ou prevalentes na formação dos conceitos científicos. Várias teorias e modelos explicativos de diferentes origens tentam explicitar essa relação. Além disso, como foi sintetizado por Delizoicov, Angotti e Pernambuco (2002), esses estudos apontam para uma diferença estrutural entre conhecimentos produzidos em diferentes relações sociais, nas quais o aprendizado de conceitos científicos não se dá isoladamente, mas como uma troca que se estabelece entre diferentes estruturas explicativas.

Se esta é uma questão recorrente no ensino e na pesquisa em ensino em geral, considerando aprendizes que compartilham um modo de vida semelhante - ainda que distinto para os diferentes grupos dentro do mesmo espaço social -, ela se torna crucial quando trabalhamos nas questões de ensino e aprendizagem de comunidades específicas, que partilham de outras formas de organização da vida, com linguagens, códigos e representações particulares. Os cursos voltados para comunidades indígenas representam um desafio e uma oportunidade de pesquisa, principalmente as licenciaturas para ensino de ciências naturais, que buscam preservar as culturas indígenas e, simultaneamente, possibilitar o acesso ao conhecimento que consideramos como científico. Uma pergunta sempre nos acompanha: que práticas pedagógicas darão conta de seus processos formativos?

A cultura a ser transmitida, discutida e apreendida na escola não é mais aquela estável e aceita por todos. Estamos, sobretudo, em busca de um trabalho intercultural, que contribua para superar atitudes de medo e de indiferente tolerância ante o "outro", construindo uma disponibilidade para uma leitura positiva da diversidade sociocultural (FLEURI, 2003). No interior das escolas encontramos abordagens e estratégias de ensino consonantes com as diversas concepções em torno do conceito de "encontro de culturas", quais sejam: uma primeira concepção, mais tradicional, em que o aluno deve aprender a cultura do outro, a que é considerada hegemônica; uma segunda, em que cada grupo mantém a sua cultura acriticamente; e, por fim, a abordagem intercultural, que sugere relações de intercâmbio, em que os diferentes são o que são em relações de negociação e conflito.

Neste trabalho é apresentada uma pesquisa realizada com alunos indígenas da segunda turma da área de Ciências da Vida e da Natureza (CVN), do Curso de Formação Intercultural para Educadores Indígenas (FIEI) da Faculdade de Educação (FaE) da Universidade Federal de Minas Gerais (UFMG). Trata-se de um curso destinado à formação de docentes indígenas, que atuarão como professores de ciências naturais e da vida nas escolas de suas aldeias. 
O currículo do FIEI/CVN se agrupa em três núcleos: o Núcleo de Formação Específica (Física, Química, Biologia, Astronomia, Geologia), o de Formação em Ciências da Educação, e o Núcleo de Formação Integradora, que engloba os componentes Estágio Supervisionado, Prática de Ensino, os Laboratórios Interculturais e os Projetos de Pesquisa. Por sua vez, cada habilitação tem uma duração de quatro anos, totalizando oito períodos de Tempo Escola (Módulo) e oito períodos de Tempo Comunidade (Intermódulo). O Módulo se realiza na UFMG duas vezes por ano, quando os alunos indígenas passam em torno de cinco semanas em atividades presenciais com os professores.

Em 2015 ocorreu a formatura da primeira turma de educadores indígenas da área CVN. A segunda turma, iniciada em 2016, é composta por trinta e cinco indígenas, das etnias Pataxó (Itapecerica/MG, Barra Velha/BA), Pataxó Hãe Hãe Hãe (Porto Seguro/BA), Guarani (Angra dos Reis/RJ), Xakriabá (São João das Missões, MG) e Maxakali (MG).

Os docentes da área CVN realizaram uma avaliação do trabalho desenvolvido ao longo de quatro anos com a primeira turma. O grupo pontuou a importância de se iniciar o trabalho com a nova turma com conceitos centrais à formação dos futuros docentes indígenas, como interculturalidade, tecnologia, saúde, território e educação escolar indígena. Para a organização do Primeiro Módulo os docentes propuseram a criação de cinco agrupamentos temáticos: Tecnologia e Trabalho, Saúde, Educação e Escola Indígena, Território e Ambiente e, por fim, Relação com o Conhecimento. Esperava-se que o debate em cada eixo auxiliaria a formatar os componentes curriculares do curso. Os indígenas foram divididos em três grupos, e ao longo de uma semana cada grupo passou por todos os agrupamentos.

O agrupamento "Relação como o Conhecimento" visava proporcionar uma troca entre os docentes e os indígenas sobre a estrutura e a validação dos conhecimentos das ciências e dos conhecimentos das diferentes aldeias. Uma problematização incipiente foi construída a partir de uma pergunta inicial: como conhecemos o mundo? Todos apresentaram suas visões de mundo sobre as diversas formas de produzir, validar e transmitir o conhecimento. As respostas dadas à indagação inicial mostraram diferenças nas descrições de alguns fenômenos ou sistemas naturais, conforme fornecidas pelos saberes tradicionais indígenas e pelo conhecimento científico. Em um determinado momento os indígenas propuseram modelos explicativos ancorados em suas culturas para interpretação dos fenômenos naturais. Percebeu-se, sobretudo, o surgimento de entidades que não são, do ponto de vista dos docentes, objetos de observação e experiência empírica. Neste momento ocorreu um silêncio na sala de aula: os indígenas renunciaram à continuidade do diálogo em sala. Perguntamos: como explicar essa fuga no silêncio? Existe alguma relação entre o silêncio percebido e o encontro intercultural?

A proposta pedagógica do FIEI possui como estratégia metodológica o diálogo entre os diferentes sistemas de conhecimento e as diversas culturas presentes. Em nossa avaliação, a proposta de formação dos professores indígenas do FIEI oferece um aporte importante tanto no que se refere ao reordenamento dos conteúdos disciplinares das escolas indígenas quanto ao problema da supremacia do conhecimento produzido no espaço acadêmico em relação a outros saberes (GOMES; MIRANDA, 2014). A falta de tradição que a pesquisa no campo educativo possui em relação ao diálogo intercultural faz com que as respostas às questões colocadas anteriormente sejam muito gerais; na maioria das vezes, sem um tratamento da complexidade em que se movem tais explicações.

O foco de nosso trabalho atual são esses momentos de silêncio que surgem em sala de aula. Anteriormente, o silêncio esteve relacionado ao conceito de educação bancária (FREIRE, 
1979). Nessa visão, o discurso científico é o único organizador das práticas escolares, fazendo com que o temor de ser mais (FREIRE, 1979) se generalize e amplie o apagamento das diferenças. Por sua vez, os conteúdos são apresentados de maneira reducionista, reforçando as representações sociais estereotipadas na construção do outro, desvalorizando-as.

Pensar no encontro de culturas distintas faz parte do pressuposto geral de um curso de licenciatura para educadores indígenas. Esperamos trazer contribuições importantes para compreender a sala de aula, tanto nos cursos de formação docente, quanto na educação básica indígena, em suas dinâmicas culturais.

\section{Outros encontros e desencontros}

Outro momento, outra cena de fuga. Em uma aula, com alunos indígenas da primeira turma do curso, ocorria uma discussão sobre as formas de manifestação e transformação de energia que ocorrem numa lâmpada acesa. A atividade tinha como metodologia promover as interações dialógicas entre alunos e professores, de forma que estes últimos evitavam fornecer as respostas diretamente. Mas surgiu um desconcerto diante da pergunta de um aluno, relacionada ao modelo microscópico da corrente elétrica: "O que acontece dentro dos fios para que a lâmpada acenda"? Após ouvir a explicação dada pelo professor, utilizando o modelo clássico da corrente elétrica, o aluno perguntou se os elementos mencionados no modelo - prótons, elétrons e nêutrons - constituíam também a mesa, as cadeiras, as pessoas, as plantas. Percebeu-se que o aluno construiu outro sentido para a fala do professor, relacionando os elementos atômicos com a essência de todas as coisas. A sua dúvida: "Prótons, elétrons e nêutrons constituíam um universal a fazer parte de todos os materiais e seres?".

No entendimento dos docentes, o diálogo envolvia determinantes culturais. Rapidamente, começaram a fazer novas perguntas ao aluno: o que ele pensava? Que resposta ele daria? E a turma, o que achava? Ao perceber a excitação gerada pela sua pergunta, o aluno renunciou ao debate. Como interpretar a relação entre as perguntas do aluno e do professor e a fuga para o silêncio nessa situação?

Inferimos que o professor considerava importante aquela discussão para se conhecer um pouco mais a cultura indígena, e por isso, ele estava com receio de que aquele conteúdo presente na voz do aluno pudesse desaparecer, uma agilidade se tornava necessária para desvendar aquele discurso. De fato, ele fez várias perguntas ao aluno em busca de explicações. Este aluno, por sua vez, aparentava fazer um esforço significativo para formular as suas ideias de uma maneira inteligível para o docente, o que acabou gerando certa tensão. Quanto mais intensa a busca pela resposta nessa interação intercultural, mais distante o professor ficava dela.

Normalmente, assumimos os pressupostos básicos de nossa cultura como tão certos que nem percebemos como eles vão se naturalizando e de que forma uma representação de mundo se torna predominante. A universalização das teorias e dos conceitos permitiu, por um lado, a acumulação da ciência, mas por outro, aprisionou elementos e conhecimentos que estavam na corrente contrária. Somos levados a crer que a ciência é a única linguagem capaz de explicar os fenômenos da natureza, e ao reduzirmos todo conhecimento à ciência, afirmamos a visão de neutralidade e objetividade como critérios de validação e demarcação entre os diversos saberes (ALMEIDA, 2010).

As experiências relatadas por Silva (2004) mostram a porta aberta por Paulo Freire (FREIRE, 1979) através de seus conceitos de estrutura dialógica, curiosidade epistemológica 
e consciência. Nesse caso, a constituição da subjetividade se dá - ou tem dificuldades para se constituir - a partir da interlocução surgida da intersubjetividade e dialogia. Nesse sentido, dialogar é falar, é dizer, não para encontrar ressonância, mas para encontrar uma palavra a partir da resposta de outro. Conforme mencionam Delizoicov, Angotti e Pernambuco (2002), a noção de diálogo em Freire está vinculada à ação e expressa um ato de criação frente aos desafios colocados pela realidade. $\mathrm{O}$ sujeito, assim, apreende a sua cultura e sua ação possibilita uma expressão inédita, criadora. Perguntamos: como pensar a sala de aula nesse contexto de diálogo intercultural? E como pensar o conhecimento científico diante dos saberes da experiência, no caso da educação indígena?

\section{A interculturalidade e a educação indígena}

No passado, os rituais e costumes escolares promoviam funções normativas do comportamento e modelavam os contornos epistemológicos da cultura e conhecimentos dominantes. Sobretudo, o contato dos povos indígenas com a cultura dominante suscitou uma visão romântica da cultura indígena, com seus modos de vida simultaneamente atrasado e passivo. A cultura etnocêntrica era a cultura a ser aprendida nas escolas. Segundo Macedo (2014), os saberes construídos nas vivências cotidianas não são considerados como capazes de ordenar e explicar o mundo, e por isso não são necessários na formatação dos conteúdos escolares. Se historicamente o encontro entre culturas distintas mostrou aspectos de confronto ou imposições de silêncios, os contatos atuais que ocorrem nos cursos de formação para educadores indígenas são espaços de negociação e de cooperação.

Pensar na interculturalidade é colocar a própria identidade em jogo, uma vez que as relações podem ser desiguais - estabelecem uma relação de poder e podem ser conflitivas -, e produtivas, já que, após o contato, as identidades se modificam (GUTIERREZ, 2014). Essa tensão conceitual é inerente à educação. No caso da educação indígena, pensamos que esse encontro pode enriquecer as identidades e as culturas, sem que uma anule a outra. Para Wagner (2012), visto que toda cultura pode ser entendida como uma manifestação específica ou um caso de fenômeno humano e que jamais se descobriu um método para "classificar" culturas diferentes, presumimos que cada cultura, como tal, é equivalente a qualquer outra. Tal contextualização sugere pensar o eu e o outro em alteridade, e implica na possibilidade de se colocar no lugar do outro, de ver como o outro, de admitir um saber que se mostra diferente dos nossos modos de conhecimento.

A partir da década de 1990 a superioridade do conhecimento científico e o desprezo pela cultura popular começaram a sofrer críticas pelos pesquisadores da educação, especialmente, da área de ciências. Para Lopes (2014), a proposição de currículos alternativos não conseguiu superar a dicotomia entre o conhecimento científico e a cultura tradicional. Porém, no que se refere à educação indígena, a cultura e os saberes tradicionais foram incorporados ao currículo escolar, trazendo novas configurações para o trabalho pedagógico. Para Cohn (2014), a escola entra na vida dos povos indígenas para atuar com seus regimes de conhecimento. Em diálogo ou em confronto com eles, a escola promove a circulação de mais conhecimentos. Nesse sentido, conhecer como o contato entre os saberes tradicionais e o conhecimento científico acontece de fato nas escolas pode nos trazer um novo olhar sobre a interculturalidade: conhecer os impasses que surgem em sala quando culturas diversas estão em interação. 
A sala de aula é pensada como "entrelugar", conceito importante retirado da obra de Homi Bhabha (BHABHA, 1998 apud FLEURI, 2003, p. 22-23): território de negociação entre culturas diferentes, entre fronteiras, isto é, um espaço ambivalente, em que os discursos se interpenetram, descartando a ideia de se pensar em um sistema estável de representação. Essa concepção de "entrelugar" é próxima do conceito de "intermediário" (KAËS, 2005). Como espaço, o intermediário é definidor de uma fronteira, ele é e não é, ele liga e mantém separado. Como uma ponte, ele mantém junto as partes heterogêneas, sem abolir as propriedades dos elementos em cada margem. O espaço intermediário é apresentado por um sujeito/grupo a outro sujeito/grupo, de modo que ele possa então ser inventado-criado por um e outro, em mútuo acompanhamento. Estamos, assim, colocando a sala de aula no mundo da cultura e das diferenças, marcada pelo silêncio e histórias reprimidas, e pela emergência de novos significantes. Buscamos, sobretudo, uma abordagem mais reflexiva para nossa pesquisa.

\section{Metodologia da coleta de dados}

Segundo Cunha (2007), quase nada ocorre no conhecimento tradicional da mesma forma como ocorre no conhecimento científico. Não há dúvida, no entanto, de que o conhecimento científico é hegemônico. A autora nos deixa a seguinte pergunta: quais as pontes entre eles?

Acreditamos que compreender a fuga no silêncio, ocorrida em determinado momento da discussão, auxilia a pensar na "ponte entre os saberes" como zona fronteiriça, uma vez que articula, simultaneamente, tanto o estranhamento quanto a expectativa de reciprocidade decorrentes da atividade naquele instante. A nossa investigação inicial era compreender a natureza da relação de cada povo indígena com o conhecimento. Porém, a produção do silêncio de uma das vozes em sala fez com que o foco se voltasse para esses momentos: entender os significados atribuídos às situações vividas, e como essas possibilitaram o reconhecimento das peculiaridades das culturas envolvidas no diálogo. Sobretudo, procuramos compreender como as interações entre as culturas que estudamos afetam as nossas próprias ações e discursos em sala de aula.

Freire (1979) nos sugere uma metodologia de pesquisa intimamente relacionada ao desenvolvimento dos processos educativos, uma vez que se mostra sutil a linha demarcatória entre a pesquisa propriamente dita e o início das atividades em sala. Conforme mencionamos, começamos a disciplina com uma indagação, e a partir desse instante construímos o objeto da pesquisa em íntima relação com as atividades propostas.

Subjacente a essa discussão, buscava-se nos diálogos os significados e valoração que são atribuídos ao conhecimento científico e aos saberes tradicionais indígenas. Esse trabalho trata exatamente do caráter crítico desse diálogo intercultural. Busca-se ouvir, na intimidade da sala de aula, as vozes silenciadas por um poder que atinge a todos. O objetivo é que a cultura indígena se torne "visível" e "plausível" para todos nós. Enquanto não pudermos "ver" essa cultura em torno de nós mesmos, ela será de pouco conforto. Dessa forma, reinventamos e damos significado à nossa própria cultura. Os nossos esforços para compreender essas pessoas, suas concepções e condutas é que produzirão significados no âmbito de nossa própria prática. Por isso, a importância de uma escuta atenta das interações discursivas que ocorreram nos momentos onde se mostraram relevantes aspectos da produção, validação e transmissão dos saberes tradicionais. Assim, em algumas partes da análise procuramos pluralizar os significados 
das cenas e discursos, principalmente, nos momentos considerados de rupturas. Esse trabalho trata exatamente da percepção e reflexão sobre a produção de conhecimento docente deste diálogo intercultural em sala de aula.

Nosso olhar para a prática como docentes do FIEI se aproxima do olhar da pesquisa de natureza qualitativa, já que buscamos apreender a complexidade dos fenômenos sociais em seu contexto. Nesse caminho, há uma maior aproximação entre pesquisador e objetos pesquisados. A pesquisa busca descrever e reconhecer os grupos em sala de aula, bem como a existência de conflitos, aproximações e afastamentos entre eles. Dois docentes e um bolsista acompanharam o grupo temático. Em sua dinâmica, o agrupamento teve dois momentos. No primeiro, os alunos, em pequenos grupos, responderam, por meio de desenhos e textos, à questão "Como conhecemos as coisas?". Em seguida, ocorreu a apresentação e o debate com todos os alunos. No segundo momento ocorreu a passagem da "Caixa-preta", acompanhada da pergunta: "Como sabemos o que tem dentro desta caixa?" Cada aluno, ao ter a caixa em suas mãos, respondia à pergunta, justificando a sua resposta. Em cada uma das atividades realizadas foi feito o levantamento das respostas dos alunos e as discussões foram anotadas pelo bolsista no diário de campo. Os textos e desenhos de cada grupo também foram recolhidos para a análise.

\section{Análise dos dados}

Após o debate sobre a questão inicial em grupos menores, ocorreu a socialização das respostas para toda a turma. No excerto que se segue encontramos as diversas formas do conhecer mencionadas pelos grupos indígenas participantes ${ }^{4}$ :
3. Conhecimento é sabedoria divina;
2. Conhecimento do pajé é dom;
2. Para utilizar o mangue, é preciso ter conhecimento;
2. Os conhecimentos tradicionais e acadêmicos se complementam;
2. Os experimentos nem sempre dão certo, pois laboratório é da vida;
1. Conhecimento dos pais que passam para a gente (cuidados, histórias);
2. É com o nascimento que a criança começa a adquirir conbecimentos, e não na escola;
1. Passam as tradicõoes e os direitos;
3. Sinais da natureza (animais e plantas)
1. Plantio: aprende-se com a convivência;
1. Observando a Lua.

Inferimos sobre a existência de vários tipos de conhecimentos, quais sejam: aqueles que são apreendidos pela transmissão oral e pela convivência (a família que passa para os filhos,

\footnotetext{
${ }^{3}$ A Caixa-preta é uma caixa de papelão, opaca e vedada, com diversos materiais em seu interior. Por meio de sua manipulação deve-se descobrir o que tem dentro dela.

${ }^{4}$ Os números que antecedem as falas referem-se aos povos indígenas presentes nos debates: Pataxós, Maxakali e Xakriabá.
} 
os sábios que passam as tradições para todos); aqueles saberes que ultrapassam os dados e os objetos, oriundos de uma capacidade que transcende o humano (dom, sabedoria divina); e, por fim, os saberes que são adquiridos pela observação da natureza (sinais das plantas e bichos, observação das fases da lua). Segundo os povos indígenas, esses conhecimentos não resultam de experimentos de laboratório, pois é a vida que os determinam, são práticos (é preciso conhecer para utilizar o mangue). Ao contrário das visões hegemônicas e etnocêntricas que fortalecem o distanciamento entre conhecimento teórico e saber prático - com o objetivo de descaracterizar este último - notamos que a concepção dos indígenas é de totalidade, uma ponte entre os diferentes. Decorre daí o fato de que os conhecimentos tradicionais e acadêmicos se complementam: um é prático, concreto, ligado à vida e se relaciona mais aos processos de aprendizagem, pois é na dedicação de cada um e a partir da observação da experiência prática que começam a aprender; o outro é abstrato, geral, não tem uma utilidade imediata no cotidiano, tratando-se mais de um processo de ensino. Mas ambos propiciam uma conexão com a natureza.

Em Delizoicov, Angotti e Pernambuco (2002, p. 135) essa diferença é atribuída também a características gerais dos tipos de conhecimento:

Ainda que a discussão sobre as características e a origem das Ciências Naturais seja objeto de estudo que oferece múltiplas interpretações, há um certo consenso que busca construir explicações balizadas por princípios como generalização, universalização e confrontação experimental ou, pelo menos, referendada na observação. Essa especificidade não faz parte de cultura prevalente ou primeira. Resultante de um amálgama de vivências, não precisa se organizar em leis e conceitos que mantenham uma relação lógica explícita nem submeter os conhecimentos que gera a um crivo sistematizado do experimental e observacional, muito menos a um critério explícito de generalização.

Sobretudo, os saberes tradicionais geram princípios, conceitos e procedimentos muitas vezes com validade só local. Explicações que mantém uma coerência narrativa que não depende de uma relação lógica explícita, mas de uma verossimilhança. Assim, são válidos e coerentes com as narrativas e as formas de explicação que remetem ao sobrenatural ou a uma não separação entre natureza, sobrenatureza e cultura.

Goody (2012) ressalta a importância de que a separação entre o divino (transcendentalidade) e o natural possui significado em nosso sistema de pensamento. Para os grupos indígenas com os quais trabalhamos, o conhecimento transcendental e o conhecimento empírico possuem continuidades entre eles, sendo o pajé ou os anciões os responsáveis por manter essa intermediação, para que a sutura seja realizada (KAËS, 2005). Conforme o diálogo mostrado na transcrição anterior, o pajé possui um saber que é dom, e por isso adquire também posição importante na aldeia: é reconhecido pela comunidade como aquele que fornece a autenticação das falas do grupo, provocando a materialização do imaterial. O pajé é sempre portador de conhecimentos transmitidos geracionalmente, revitalizando os saberes tradicionais.

Como transmitem sua cultura e seus modos de viver para as gerações mais novas? Estas não apenas se apropriam da cultura, mas também se abrem para outras formas de pensar. Transmitidos de geração em geração, é com o nascimento que a criança começa a adquirir conhecimentos, 
e não na escola. Tal fato mostra que os saberes tradicionais indígenas carregam aspectos práticos sobre a natureza e sobre as atividades sociais e econômicas, e que são passados de forma lenta e gradual desde os primeiros anos da vida familiar. Centrada no interesse, concepção e dedicação do sujeito, a aprendizagem se faz pela observação, imitação e seguindo as orientações dadas pelos mais experientes na convivência conjunta das práticas sociais:

P1: Mas como eu sei que uma planta é boa para alguma coisa que a pessoa está sentindo? 2. Meu pai falou. Conhecimento vem desde o nascimento. Baseado no ensinamento dos pais. A criança vai para a roça, primeiro para observar. A profissão ele aprende a partir da convivencia com o grupo;

3. A mãe ensina a criança tecer e o pai a fazer os arcos, as flechas, os cantos.

Segundo o excerto anterior, a partir das vivências durante a infância, as crianças começam a ouvir com mais atenção os discursos, as cantigas e outros ensinamentos que são transmitidos oralmente. O pai e a mãe cumprem seu papel de passar informações, promovendo a inserção da criança na vida familiar e na atividade econômica. Após essa pequena discussão o diálogo entre docentes e alunos cessou, como se a resposta fosse suficiente. Estamos frente a uma "falta" na comunicação, rapidamente contornada pelos docentes. Coube a estes criarem uma continuidade na discussão com uma pergunta relacionada à influência da lua para a agricultura. Vejamos:

P2: Como é que eu sei que uma lua tal é boa para se plantar?

2. Observando a lua. Foi sendo passado de geração a geração. Foram observando, e testando, como a ciência fa\%:

3. Os pais ensinam. Se a mulher ganhar o bebê durante a lua cheia, será menino; se na lua nova, menina.

Observamos uma tentativa do aluno em aproximar as duas formas de conhecer o mundo, de mantê-las juntas em sala de aula. Em primeiro, a forma de produzir o conhecimento: observando e testando, como a ciência far. Nesse caso, a metodologia forneceria legitimidade tanto ao conhecimento científico quanto aos saberes tradicionais. Em segundo, a transmissão do conhecimento implica, também, em sua validação: se o conhecimento não fosse válido ele não seria transmitido. Essas duas condições permitem a formulação de um saber que é fruto da transmissão (os pais ensinam) e de uma metodologia de cunho empirista (Se a mulher ganha o bebê durante a lua cheia será menino; se na lua nova, menina). Segundo o aluno indígena, o saber tradicional, tal como o conhecimento científico, é um saber verdadeiro e válido. Mesmo que o critério de validade possa ser a consistência interna com uma visão de mundo, os dois juntos fornecem uma visão holística na explicação do cotidiano. Na continuidade, o diálogo travado reforçou a observação atenta da natureza associada à transmissão do conhecimento:

2. Escutando os pássaros vem chuva.

P2: Como descobriram?

2: Aprenderam com os mais velhos, que aprenderam com os mais velhos. 
O conhecimento é transmitido e, simultaneamente, observado. Porém, o último excerto mostra que poderia haver um conhecimento sem origem, que vem sendo passado há muitas gerações. De certa forma, nas culturas caracterizadas pela oralidade, a memória da autoria, embora nunca totalmente ausente, nem sempre tem a importância que se espera dela. Tal aspecto permite que haja recriações por meio da incorporação de variações próprias. Teríamos, assim, várias versões locais corretas.

Em nosso entendimento, a partir desse momento aconteceu uma mudança no rumo do debate: os indígenas passaram, além de descrever as regularidades, a fornecerem explicações para os fenômenos observados. Nos diálogos em sala ressurge, por parte de dois grupos indígenas, um conhecimento que é espiritual e mítico. Vejamos:

\section{Pajé conhece as plantas, é um conhecimento espiritual; \\ P1: Como se passaria o conbecimento espiritual?}

3. Não se aprende só de se sentar com os anciãos. Tem que ter o dom também;

1. Pelos Sonhos;

3. Espiritualidade vem da força da natureza.

Percebemos, sobretudo, o surgimento de conhecimentos que são validados pelas forças espirituais, fato este que habitualmente materializa certo estranhamento quando explicitado. Em nossa interpretação, a existência de mecanismos atribuídos à ação e observação capazes de relacionar meios e fins que são distintos da empiria, fez surgir algumas crenças: a presença de um conhecimento mítico. Conforme já mencionamos, a transmissão do conhecimento tendo como intermediação o pajé ocorre pelo dom, pelos sonhos e pela espiritualidade. Enfim, a transmissão se dá pela intervenção de entidades "sobrenaturais", capazes de promoverem a coesão social sob a tutela de uma transcendência, que é a do diálogo entre natureza, espírito e dom (GOODY, 2012). Deparamos aqui com o registro de um silêncio desconfortável diante dessa cosmogonia. Perguntamos: de onde surgiu esse silêncio? Que explicação pode ser sugerida para seu aparecimento?

Acreditamos que discutir apenas a descrição dos fenômenos implicava em satisfazer padrões lógico-experimentais, e não se adentrar em aspectos culturais ou em crenças, o que tornava gratificante o debate e os acordos que os sustentavam, bem como os diálogos que provocavam em sala de aula (KAËS, 2005). Os docentes focados na discussão do conhecimento empírico e dos saberes advindos da observação não perceberam a mudança na sequência discursiva, isto é, o surgimento de teorias e cosmogonias que ultrapassavam a experiência. $\mathrm{Na}$ continuidade, os indígenas mencionaram que a produção do conhecimento, a sua transmissão e a sua apropriação necessitavam de um conhecimento espiritual que transcende o objeto, que vem da natureza, e que, dependendo de sua relevância para a comunidade, é transmitido pelos "sonhos" apenas para alguns iniciados, aqueles que possuem o "dom" suficiente. A nossa suposição é que a falta de uma escuta docente levou ao silêncio. Em nossa interpretação, houve uma ruptura quando os indígenas deram uma resposta além da dimensão descritiva, e que gerou um descompasso em sala. Escutar implicaria em questionar a coerência entre as formas de pensar e agir de cada povo, o que promoveria a comparação entre as culturas ali presentes. O distanciamento do cotidiano é ampliado pela transcendência erigida, afastando a explicação 
dos fenômenos da ação do homem e, talvez por isso, causa do estranhamento. A explicação, por meio de entes transcendentais e forças espirituais, talvez estivesse recalcada anteriormente nas interações entre docentes e alunos, constituindo-se em um pacto de denegação (KAËS, 2005). Indagamos: quando se chega aos modelos explicativos o conflito que surgiu se deve à existência de teorias hegemônicas sobre outras?

Não há, aqui, um abandono de uma explicação mágica, mística ou religiosa, provocadora de uma busca de outras razões para os fatos. Trata-se de um acontecimento que produziu uma sobrecarga nos docentes, colocando-os diante de situações que não podem resolver com as pautas tradicionais. Porém, em nosso entendimento, os alunos indígenas só mencionaram tais concepções porque se sentiram à vontade em dizê-las, pois o espaço fronteiriço que a sala de aula representa estava bem delineado, se constituindo como um espaço ventilado, onde as ausências e presenças de narrativas enriquecem as culturas em jogo. $\mathrm{O}$ silêncio surgiu como um aumento de pressão sobre os participantes.

Uma vez que a concretização do silêncio ocorreu, adquirimos uma maior consciência das formas e manifestações das diferenças e similaridades implicadas na distinção entre os conhecimentos. $\mathrm{O}$ fato que se mostra interessante é a continuidade da aula sem agressividades, o que evidencia a presença de um tipo de aliança no grupo (KAËS, 2005): a negatividade. Essa tem a função de encobrir conteúdos que devem ser esquecidos, para assegurar o acordo de convivência que confirma a desigualdade entre as partes. Assim, a convivência é mantida e tornada viável quando é negado aquilo que impediria a própria convivência, ou seja, a persistência da própria desigualdade. Manteve-se a paz, embora as partes não conseguissem dialogar sobre o tema. Mas assegurar os vínculos que sustentam a zona fronteiriça permite a discussão sobre a desigualdade em outros momentos.

Após o desconforto vivido, os docentes conversaram entre si e fizeram a apresentação da caixa-preta, como instrumento capaz de promover a continuidade da aula:

P2: Como é que a gente far para transmitir para alguém, para as novas gerações, o que tem dentro da caixa? Seremos os primeiros sábios. Como é que eu vou descobrir?

Um dos professores apresentou uma pequena caixa de papelão, opaca e vedada, perguntando aos alunos o que ela continha. Após o manuseio da caixa, as respostas eram dadas e o professor fazia os registros no quadro. As respostas eram as mais diversas: bolinhas, cubos, tampinhas, apontadores, lápis, borrachas, esferas (de metal, de vidro, de plástico, de madeira), materiais em configurações mais complexas (uma bolinha dentro de uma caixinha de metal). A cada resposta, o professor perguntava qual a justificativa. Nesse momento, o professor discutia com os estudantes as principais questões da atividade: "Como conhecemos as coisas? Temos certeza do que tem dentro da caixa?".

P2: Alguém, em algum momento, começou a observar a natureza. Vejamos que não é fácil fažer certas observações. As astronômicas, por exemplo. Passaram-se muitos anos para que uma hipótese pudesse ser feita e confirmada. O sol vai nascer amanhã? Como sabemos?

2. Pela observação [responde um estudante].

P2: E no caso da caixa, a observação serve?

2. Passo a usar a imaginação a partir do que eu conheço. 
A resposta do aluno trouxe um elemento diferente da observação como forma de produção de conhecimento: "Passo a usar a imaginação a partir do que eu conheço". Foi nessa resposta que os docentes se apoiaram para introduzir a ideia de teoria e modelo, ou seja, mencionaram outra forma de interpretar e pensar a causalidade que se observa nos fenômenos. Para tanto, novas questões foram incorporadas ao debate pelos docentes: O Sol vai nascer amanhã? Como sabemos?

As questões trazidas pelos docentes tinham como objetivo explicitar um pouco mais a causalidade, isto é, como os saberes tradicionais e o conhecimento científico explicavam o fato do sol nascer todos os dias. Para os astecas, o Sol não poderia parar de nascer, pois provocaria uma ruptura grande na ordem harmoniosa do universo. Mas eles não tinham a certeza, pela simples observação, de que o sol nasceria todos os dias. Precisavam de um mediador espiritual: faziam sacrifícios humanos destinados a garantir o seu nascimento. Após esse breve relato explicativo, os docentes fizeram em sala a seguinte pergunta: "Será que para a ciência o simples fato do Sol nascer todo dia basta para que ele nasça amanhã?’. Nesse nível, a explicação se deu pelo modelo da gravitação universal. Encontramos, na sequência, a fala do docente:

P2: Os conhecimentos que temos vêm de maneiras diferentes. Por exemplo, sobre o sol aparecer amanhã com certeza. Uma maneira de saber isso épela observação. Mas, preciso mais do que observação: preciso também da imaginação. Elaboramos modelos, uns mais complexos, outros mais simples.

A discussão caminhou na direção tanto da diferenciação das formas de conhecer o mundo, quanto pelo fato de abrir a caixa ou não. Porém, virou um debate entre os dois professores, que comentaram sobre as formas do saber, de sua produção e dos processos de validação:

P1: A ciência é capaz de abrir a caixa? Para conhecer as coisas é preciso abrir a caixa? Ao longo do curso, temos que pensar se algum conbecimento abre a caixa, seja ele o científico ou o tradicional. Ambos são crenças, e que também podem mudar [não são imutáveis].

P2: Mas qual é a melhor explicação? A científica ou a tradicional? As explicações não são comparáveis. Não tem como comparar os conhecimentos. Mas, durante o curso, eles serão tensionados.

P1: Como sabemos que a lua influencia o corte de cabelos, o nascimento dos filhos? São crenças/valores.

P2: A astronomia é uma prática para os indígenas. Interfere no cotidiano, nas relações de trabalho. Em vários momentos vamos nos deparar com essas questões. O sol nasce todo dia, pois foi assim há bilhões de anos: observação. A partir de certo momento, a ciência passon a explicar de uma outra forma. O conbecimento baseado só na observação não é suficiente, ainda que não seja invalidado por isso.

P1: Algum desses conbecimentos (tradicional e/ ou cientifico) é sempre capaz de comprovar, de dizer qual é a verdade?

P2: As teorias mudam: a ciência é também uma construção de um grupo de pessoas que foi se perpetuando ao longo do tempo. 


\section{Conclusões}

\section{Novos conhecimentos, outras práticas}

Percebemos como a sala de aula se tornou o espaço fronteiriço entre as culturas, onde a diversidade deve ser mantida, bem como o local de investimentos pelos sujeitos envolvidos. Nosso interesse é conhecer o que permite gerenciar os ditos e não ditos nestes espaços, provocadores de conflitos e silêncios, sem provocar desligamentos e cisões no grupo.

Em função das vivências com as duas turmas CVN, percebemos que duas dimensões se configuraram de grande importância. A primeira, a dimensão teórico-conceitual, com a prevalência de aportes epistemológicos e metodológicos das dinâmicas interacionistas, caracterizadas pela não dissociação método-conteúdo (DELIZOICOV; ANGOTTI; PERNAMBUCO; 2012). Em segundo, a dimensão sociocultural e emocional, marcada pelo acolhimento e acompanhamento dos alunos indígenas pelos docentes e bolsistas envolvidos no curso. Cada uma se percebe capaz de atuar para a instauração de um laço que deixa um espaço para que o conflito e a diferença possam se exprimir. Cabe mencionar que, mesmo os pressupostos de que nos valemos, de viés participativo e de fortalecimento dos sujeitos e da cultura indígena, foram repensados à medida que as trocas mantidas com as turmas indígenas nos faziam rever os contatos culturais e a própria viabilidade e visibilidade do diálogo intercultural em toda a sua complexidade. Vejamos algumas dessas atividades e práticas que permitiram os movimentos de aproximação entre os grupos e seus discursos.

Uma dessas práticas relacionava-se às formas de se estudar a origem do mundo e do sistema solar em sala. Dividida a sala em vários grupos, cada um deles recebia uma forma de explicar o mito das origens por crenças diversas: científica, religiosas e povos indígenas. Após discutir as formas de explicar o seu mito, cada grupo apresentava para os colegas as suas explicações, confrontando ou complementando as teorias envolvidas.

Em segundo, a discussão construída numa Disciplina do curso com o tema "Alteridade, Saberes da Experiência e Cultura Acadêmica". A quebra dos laços e da continuidade entre os sujeitos e destes com os objetos foram questionados pela leitura e discussão do texto "Os ritos corporais entre os Nacirema", na qual a cultura branca europeia é transformada numa cultura cuja aprendizagem e vivência dos saberes que perpassam os modos de vida são marcadas pela inexistência de pactos e contratos, e assim, são repletas de situações agressivas e violentas (KAËS, 2005). O texto provocou uma discussão aprofundada sobre a interculturalidade.

Em terceiro, uma disciplina ministrada por dois docentes: um da área CVN e outro da Antropologia. O planejamento realizado em conjunto permitiu a construção de atividades com mais de um olhar e a criação de situações de diálogos interculturais a partir da pergunta inicial: "Devemos ou não tomar água fervida para se evitar doenças?". A diversidade de ações propostas (questões problematizadoras e, para debates, leituras de textos sobre interculturalidade, filmes, realização de uma pesquisa etnográfica) teve como pano de fundo o debate entre os saberes tradicionais indígenas e o conhecimento científico.

Por fim, a manutenção de planejamentos coletivos da Área CVN, com a escolha de conceitos comuns a todas as disciplinas: energia, saúde, território, tecnologia e cultura. São estes temas/conceitos que se mostraram transversais a todas as disciplinas e forneceram concretude às ações desenvolvidas. 


\section{Quem tem medo das contingências?}

Mostramos as relações entre os saberes tradicionais e o conhecimento científico em uma disciplina do curso de formação para educadores indígenas. Inferimos que as origens e a produção dos saberes indígenas estão além da mera observação dos fatos e da busca de regularidades nos fenômenos, marcados, muitas vezes, pelas suas concepções de mundo. A relação com as entidades transcendentais e forças da natureza, bem como a presença constante da imaginação na formatação daqueles saberes, fornecem outra inteligibilidade à sistematização e apropriação dos dados observados nas diversas atividades do cotidiano. Geertz (2014, p. 79), ao escrever sobre o senso comum, menciona que "faz parte dessa estrutura de pensamento afirmar que suas opiniões foram resgatadas diretamente da experiência, e não um resultado de reflexões deliberadas sobre esta". A análise do senso comum inicia-se, segundo o autor, na reformulação da distinção entre uma mera apreensão da realidade e uma sabedoria da experiência, que julga e avalia esta realidade. Muitas vezes são essas crenças nas "forças da natureza" ou do "espírito" que são utilizadas como argumentos para ridicularizar os saberes tradicionais e para mostrar que os povos "mais simples" têm um interesse imparcial no conhecimento, bem como uma apreciação da beleza por si mesma (GEERTZ, 2014).

Entender a multiplicidade das formas de conhecer e transmitir os saberes estabiliza um pouco mais a nossa compreensão da cultura indígena. Aprendemos que existem conhecimentos produzidos pela espiritualidade e pela força da natureza, que podem ser transmitidos pelos sonhos, também vistos em outros povos indígenas (ANDRELLO; FERREIRA, 2014). Existem, também, saberes que são passados entre os corpos por meio de ferroadas de formigas (OLIVEIRA; SANTOS, 2014). Além disso, a concepção dos guaranis de que existem conhecimentos espalhados pelo corpo, que não são exclusivos ao cérebro, é contrária a algumas concepções mentalistas presentes em alguns ramos da ciência. Nessa concepção, existem saberes que são parcialmente transmitidos anteriormente ao nascimento (OLIVEIRA; SANTOS, 2014). Ao conviver com essa diversidade de concepções sobre a produção, transmissão e validação dos saberes tradicionais indígenas, nós e formadores docentes vivemos em constantes processos de diferenças e convergências. E são os silêncios decorrentes da (não) comunicação entre essas visões de mundo que observamos em nossas práticas docentes. Vejamos o que ocorre durante o encontro entre essas culturas e os saberes acadêmicos em contextos escolares:

a) Notamos a concepção presente entre os povos indígenas de que o conhecimento tradicional é diferente do saber científico, devido ao fato de que um é prático e concreto, e o outro é abstrato, produzido em laboratório. Porém, eles se ligam e se mantém separados, pois "um completa o outro", do ponto de vista de suas concepções. Como uma ponte, ele mantém junto as partes heterogêneas, sem abolir as propriedades dos elementos em cada margem (KAËS, 2005). Ambos são considerados próximos, devido ao fato de que partem da observação e da repetição dos dados, que funciona como critério de validação. Ressaltamos que essas concepções também são compartilhadas nas diretrizes e concepções de nossas escolas urbanas, porém com a valorização apenas dos saberes acadêmicos em detrimento da cultura popular, pois trazem juntos uma concepção positivista da ciência, na qual tanto os saberes tradicionais quanto o conhecimento científico devem ser admitidos. Segundo El-Hani e Sepúlveda (2006), a recente preocupação em desenvolver currículos de ciências que leve em conta as interações entre cultura e educação científica implica na superação do cientificismo nas aulas de ciências; 
b) Percebemos, também, pelos diálogos travados em sala, que uma das formas de validação do conhecimento tradicional é sua transmissão pelos mais velhos;

c) A insistência, por parte dos docentes, em trazer para a discussão um conhecimento que pudesse não ser produzido exclusivamente pela observação provocava, ainda, um clima de desconforto entre os indígenas;

d) A não-escuta, pelos docentes, de uma parte dos excertos indígenas em que mencionaram o pensamento mítico está relacionada aos pressupostos mais básicos de nossa cultura, os quais são assumidos com tal certeza que nem nos apercebemos de outras visões que surgem em nosso cotidiano. O silêncio dos alunos refletiu essa postura de não-escuta pelo docente. Conforme nos traz Goody (2012), devemos avaliar que essa separação entre o natural e o sobrenatural só possui sentido dentro de nosso jeito de pensar, e que pode existir continuidade entre o conhecimento sobrenatural e conhecimento empírico em outras culturas. Concluímos que, nesses momentos, as culturas em sala se tornaram sem contato, exteriores entre si.

A questão que perseguimos é se as atividades curriculares propostas deixaram intacto ou não o currículo hegemônico. Assim, compreender os entrincheiramentos torna-se parte essencial dessa pesquisa. Porém, as relações de agressividade que podem surgir nessas situações foram debeladas devido ao apoio que encontraram nos vínculos presentes nos processos de intermediação e confiança que os grupos construíram entre si (KAES, 2005). Percebemos não apenas as formas de cada povo indígena e as relações entre si e com o conhecimento, como também os momentos de silêncio ocorridos ao longo dos debates. Compreender essas situações, a posteriori, nos levou não apenas a valorizar a cultura do outro, mas a ter a sensibilidade de ver pelos olhos daqueles alunos. Perceber um saber que é também invenção e fruto da imaginação, e não apenas da observação e descoberta dos fatos. Porém, diferentemente das teorias científicas que fornecem os modelos explicativos dos fenômenos, aqui deparamos com as forças do espírito e da natureza para se ir além das regularidades observadas. São as pedras vivas, nos dizeres de Cunha (2007, p. 78):

O conhecimento científico se afirma, por definição, como verdade absoluta até que outro paradigma o venha sobrepujar, como mostrou Kuhn. Essa universalidade do conhecimento científico não se aplica aos saberes tradicionais - muito mais tolerantes - que acolhem frequentemente com igual confiança ou ceticismo explicações divergentes cuja validade entendem seja puramente local. "Pode ser que, na sua terra, as pedras não tenham vida. Aqui elas crescem e estão, portanto, vivas".

E o mais difícil foi compreender, a partir dos exemplos e vivências, que professores e bolsistas estão numa posição complexa, de quem se propõe um diálogo horizontal entre os saberes tradicionais e o conhecimento científico e, ao mesmo tempo, participam da cultura hegemônica. Apesar dos impasses, acreditamos que a sala de aula, enquadrada pelo diálogo intercultural, foi capaz de conter a turbulência silenciosa. Para Wagner (2012), a cultura se torna visível pelo choque cultural, pelo ato de submeter-se a experiências que excedem a nossa competência ordinária. Uma vez que a concretização ocorre, o pesquisador adquire uma consciência intensificada dos tipos de diferenças e similaridades implicadas pelo termo "cultura" e começa a usá-lo cada vez mais como um constructo explanatório. Ele começa a ver seu próprio modo 
de vida em nítido relevo contra o pano de fundo das outras "culturas" que conhece. Trazemos à tona, com esse trabalho, uma diversidade de histórias locais, os modos diferentes de produção e transmissão de conhecimento, e algumas concepções não científicas que também se voltam para a resolução de problemas do cotidiano. Não é tão simples pensar no encontro dessa diversidade de saberes em nossas escolas.

Não temos a intenção de conhecer ou determinar, a priori, os momentos de silêncio, ou mesmo classificá-los. Existe uma impossibilidade de se pensar ou de se fixar essas caracterizações ao longo do curso. Haverá sempre uma dúvida sobre o que este "momento de silêncio" realmente representa, em virtude da contingência da metodologia ou da nostalgia da certeza perdida. Porém, as conclusões deste trabalho nos habilitam a conviver com as dúvidas e as angústias de todos que vivem nos espaços fronteiriços. Quando achamos que tínhamos as respostas surgiram outras situações, reforçando a ideia do ser mais (FREIRE, 1979).

Então, o que deve fazer parte na educação dos povos indígenas? Após acompanharmos as tensões e os impasses vividos, parece que a formação do docente indígena implica duas rotas, interligadas entre si. A primeira revela-se no fortalecimento do eu, exatamente para dar conta das incertezas surgidas no cotidiano. A segunda rota refere-se a um processo de formação que não se resume em mera acumulação dos conteúdos disciplinares, e sim nas vivências de respeito e enriquecimento recíproco das culturas.

A educação intercultural é compreendida como mecanismo marcado por uma relação tensa entre sujeitos diversos, propiciando contextos ora interativos ora mais "silenciosos", significando maior ou menor espaço simbólico onde se constrói um ambiente mais ou menos criativo. E o que teriam em comum? Segundo Cunha (2007), uma resposta é que o conhecimento científico e o saber tradicional são formas de procurar entender e agir sobre o mundo. E também são obras abertas, inacabadas, sempre se fazendo. Para a autora (CUNHA, 2007, p. 84), devemos "encontrar uma forma para o conhecimento científico e o conhecimento tradicional viverem juntos. Viverem juntos não significa que devam ser considerados idênticos. Pelo contrário, seu valor está justamente na sua diferença".

\section{Referências}

ALMEIDA, M. C. Complexidade, saberes científicos, saberes da tradição. São Paulo: Livraria da Física, 2010.

ANDRELLO, G.; FERREIRA, T. A. Transformações da cultura no alto rio Negro. In: CUNHA, M. C.; CESARINO, P. N. (Org.). Políticas culturais e povos indígenas. São Paulo: Cultura Acadêmica, 2014. p. 25-58.

COHN, C. A cultura nas escolas indígenas. In: CUNHA, M. C.; CESARINO, P. N. (Org.). Políticas culturais e povos indígenas. São Paulo: Cultura Acadêmica, 2014. p. 455-483.

CUNHA, M. C. Relações e dissensões entre saberes tradicionais e saber científico. Revista USP, São Paulo, n. 75, p. 76-84, 2007. Disponível em: <http://www.journals.usp.br/revusp/ article/download/13623/15441>. Acesso em: 5 out. 2018.

DELIZOICOV, D.; ANGOTTI, J. P.; PERNAMBUCO, M. M. Ensino de ciências: fundamentos e métodos. São Paulo: Cortez, 2002. 
El HANI, C. N.; SEPULVEDA, C. Referenciais teóricos e subsídios metodológicos para a pesquisa sobre as relações entre educação científica e cultura. In: SANTOS, F. M. T.; GRECA, I. M. R. (Org.). A pesquisa em ensino de ciências no Brasil e suas metodologias. Ijuí: Unijuí, 2006. v. 1, p. 161-212.

FLEURI, R. M. Intercultura e educação. Revista Brasileira de Educação, Rio de Janeiro, n. 23, p. 16-35, 2003. Disponível em: <https://doi.org/10.1590/S141324782003000200003>. Acesso em: 5 out. 2018.

FREIRE, P. Pedagogia do oprimido. Rio de Janeiro: Paz e Terra, 1979.

GEERTZ, C. O saber local: novos ensaios em antropologia interpretativa. 14. ed. Petrópolis: Vozes, 2014.

GOMES, A. M.; MIRANDA, S. A. A formação de professores indígenas na UFMG e os dilemas das 'culturas' entre os Xakriabá e os Pataxó. In: CUNHA, M. C.; CESARINO, P. N. (Org.). Políticas culturais e povos indígenas. São Paulo: Cultura Acadêmica, 2014. p. $455-484$.

GOODY, J. O mito, o ritual e o oral. Petrópolis: Vozes, 2012.

GUTIERREZ, A. L. G. Notas conceituais sobre a relação entre justiça curricular e currículo intercultural. In: LOPES, A. C.; ALBA, A. (Org.). Diálogos curriculares entre Brasil e México. Rio de Janeiro: EdUERJ, 2014. p. 65-82.

KAËS, R. Os espaços psíquicos comuns e partilhados: transmissão e negatividade. São Paulo: Casa do Psicólogo, 2005.

LOPES, A. C. Ainda é possível um currículo político? In: LOPES, A. C.; ALBA, A. (Org.). Diálogos curriculares entre Brasil e México. Rio de Janeiro: EdUERJ, 2014. p. 43-64.

MACEDO, E. Currículo, cultura e diferença. In: LOPES, A. C.; ALBA, A. (Org.). Diálogos curriculares entre Brasil e México. Rio de Janeiro: EdUERJ, 2014. p. 83-104.

OLIVEIRA, J. C.; SANTOS, L. K: "Perguntas demais": multiplicidades de modos de conhecer em uma experiência de formação de pesquisadores guarani MBYA. In: CUNHA, M. C.; CESARINO, P. N. (Org.). Políticas culturais e povos indígenas. São Paulo: Cultura Acadêmica, 2014. p 113-134.

SILVA, A. F. G. O currículo na educação popular: a perspectiva ético-crítica para além das disciplinas. In: CONGRESSO MUNICIPAL DE EDUCAÇÃO, 3., 2004, São Paulo. Atas... São Paulo: SME, 2004.

WAGNER, R. A invenção da cultura. São Paulo: Cosac Naify, 2012.

Artigo recebido em 21/12/2017. Aceito em 01/08/2018.

Contato: Universidade Federal de Minas Gerais, Faculdade de Educação, Avenida Antonio Carlos, 6627, Belo Horizonte, MG, 31270-901, Brasil. 
